\title{
Fotografia e valor documentário: o arquivo de Carlos Chagas
}

\author{
Photography and documental value: the \\ Carlos Chagas archive
}

\author{
Aline Lopes de Lacerda \\ Pesquisadora da Casa de Oswaldo \\ Cruz/Fundação Oswaldo Cruz \\ Departamento de Arquivo \\ Av. Brasil, 4036/616 \\ 21040-900 - Rio de Janeiro - RJ - \\ Brasil \\ lacerda@coc.fiocruz.br
}

LACERDA, Aline Lopes de. Fotografia e valor documentário: o arquivo de Carlos Chagas. História, Ciências, Saúde - Manguinhos. Rio de Janeiro, v.16, supl.1, jul. 2009, p.115-138.

\section{Resumo}

Examina questões metodológicas referentes ao tratamento técnico de arquivos, a partir da organização do arquivo de Carlos Chagas. Tendo como objeto as fotografias integrantes dessa documentação, discute a organização arquivística de fotografias e analisa alguns grupos dessas imagens, com enfoque nas fotografias relacionadas à descoberta da doença de Chagas em Lassance. O objetivo é verificar os processos de produção de sentido embutidos na metodologia de classificação desses documentos. Aponta em que medida as imagens relacionadas à estadia de Chagas em Lassance - para onde ele foi inicialmente combater a malária - assumiram novo sentido, diante da importância da descoberta da doença para a sua trajetória e na produção e disseminação de sua memória.

Palavras-chave: fontes históricas; arquivos fotográficos; Carlos Chagas; doença de Chagas; memória.

\begin{abstract}
Centered on the organization of the Carlos Chagas archive, the article explores methodological concerns in the technical handling of such material. It discusses the archival organization of photographs and analyzes some groups of images from the Chagas archive, particularly photographs concerning the discovery of Chagas' disease, in Lassance, where the scientist initially went to combat malaria. The goal is to identify processes of production of meaning that are built into the methodology for classifying these documents. The article examines to what extent the images of Chagas' stay in Lassance took on new meaning because of the weight this discovery had on the scientist's career and likewise on the production and dissemination of his memory.
\end{abstract}

Keywords: historical sources; photographic archives; Carlos Chagas; Chagas' disease; memory.

Recebido para publicação em dezembro de 2008. Aprovado para publicação em maio de 2009. 
A fotografia não é, por natureza, um documento. ... por outro lado, cada imagem guarda um valor documentário que, longe de ser fixo e absoluto, deve ser apreciado na sua variabilidade no interior de um regime de verdade - um regime documentário.

André Rouillé, La photographie, p.25

\begin{abstract}
A comemoração dos cem anos da descoberta da doença de Chagas, em 2009, gerou uma série de iniciativas com o intuito de conferir à efeméride - a partir da evocação da imagem de Carlos Chagas (1878-1934) e da discussão dos temas principais de sua trajetória, em especial da pesquisa sobre a doença que leva seu nome - a importância histórica que lhe é devida. Um desses movimentos refere-se à organização e disponibilização, para consulta, do arquivo pessoal de Carlos Chagas, sob custódia da Casa de Oswaldo Cruz (COC) da Fundação Oswaldo Cruz (Fiocruz). Durante dois anos uma equipe do Departamento de Arquivo e Documentação da $\mathrm{COC}^{1}$ reuniu-se em torno dessa documentação, para discutir seus contornos, identificar as temáticas nela representadas, entender seus contextos de produção e procurar identificar as conexões entre os distintos documentos e as funções exercidas pelo cientista ao longo de sua vida. Esse esforço culminou na elaboração do inventário do arquivo, instrumento de pesquisa que possibilita o acesso aos usuários em geral e cuja publicação está prevista como parte das atividades comemorativas do referido centenário.
\end{abstract}

Algumas considerações sobre a história da produção e acumulação desse arquivo são oportunas, para que sejam conhecidos os caminhos que a documentação trilhou até o momento de organização e subsequente abertura pública à consulta. $\mathrm{O}$ arquivo foi doado à COC, no início dos anos 90, por Carlos Chagas Filho (1910-2000), filho caçula do cientista que, desde a morte do pai e do irmão, Evandro Chagas (1905-1940), tornou-se o guardião da memória familiar, mantendo a documentação reunida e utilizando-se dela em projetos específicos. ${ }^{2}$

O conjunto, que continha documentos de Carlos Chagas e também de Evandro, foi objeto de uma primeira organização como arquivo familiar, por se entender, à época, que assim seriam conferidas a ênfase e a visibilidade que mereciam os documentos daqueles que, além de importantes personagens da história da ciência e da saúde pública, eram membros de uma mesma família. A classificação atribuída então ao arquivo separou os documentos textuais por séries temáticas, e as fotografias foram dispostas em dossiês temáticos num arranjo cronológico e transferidas para a Seção Iconográfica, procedimento de organização amplamente utilizado por instituições que mantêm arquivos.

Com a morte de Chagas Filho em 2000 e de sua esposa Anna Leopoldina de Mello Franco Chagas (1914-2008), uma extensa documentação, doada pela família, veio somar-se ao conjunto arquivístico que já se encontrava sob a guarda da COC. Tal situação, somada à aproximação das comemorações do centenário da descoberta da doença de Chagas, reforçou a necessidade de serem revistas as formas de organização dessa documentação. Outro motivo relevante foi a necessidade de compreender os contornos desse acervo, tratado anteriormente como 'familiar', agora levando-se em consideração a identificação e separação 
das titularidades ${ }^{3}$ de produção dos documentos - tanto do pai, quanto de cada um dos filhos. ${ }^{4}$

Além disso, fazia-se oportuna essa revisão diante da implantação, na COC, de outro método de organização dos arquivos pessoais sob sua guarda, diretriz que a Casa vem seguindo nos últimos anos. A nova metodologia para organização desses documentos cartas, telegramas, relatórios, textos de pesquisa, conferências, palestras, diplomas, designações, nomeações, fotografias, entre outros itens - baseia-se nas funções e atividades exercidas pelos cientistas e não mais por temas ${ }^{5}$, como anteriormente. Tal método - baseado exclusivamente no modelo funcional - preconiza também a integração de todos os documentos, independentemente de seu gênero ou tipo, na fase de organização, não existindo mais o tratamento específico por suporte documental, tão comumente aplicado ao material iconográfico integrante da maioria dos arquivos.

Assim, o fundo Carlos Chagas foi reclassificado a partir dos seguintes grupos documentais: Vida Pessoal; Formação Acadêmica; Administração da Carreira; Docência; Pesquisa; Gestão de Ciência e Saúde Pública; Relações Interinstitucionais e Intergrupos. Cada um desses grupos foi dividido em subgrupos, atividades, funções, até chegar ao último nível, a série, que agrupa os documentos por tipologia.

A partir da perspectiva de reorganizar e 'refazer' o arquivo é que inserimos a questão central deste trabalho, que não tem como foco uma análise do arquivo de Carlos Chagas como um todo, mas incide sobre a documentação de caráter visual - notadamente fotográfica -, integrante desse arquivo. Mais especificamente, detém-se sobre as questões suscitadas pela integração desse material na organização geral, a partir do cumprimento de diretrizes metodológicas de tratamento arquivístico.

Este artigo está dividido em duas partes. Na primeira apresento, de forma introdutória, algumas questões sobre o método de organização arquivística de fotografias. Na segunda parte, parto para um enfoque no trabalho de organização das imagens fotográficas no arquivo de Chagas, analisando alguns grupos de imagens e, privilegiadamente, as imagens relacionadas à descoberta da doença de Chagas em Lassance (MG), com o objetivo de discutir os processos de produção de sentido embutidos na metodologia de classificação desses documentos. Apontaremos em que medida as imagens relacionadas à estadia de Chagas em Lassance, referida inicialmente ao combate à malária, assumiram novo sentido diante da centralidade que a descoberta da doença que o consagraria teve em sua trajetória e, consequentemente, na produção e disseminação de sua memória.

\section{Discutindo o tratamento das imagens nos arquivos}

A discussão sobre organização de documentos fotográficos é importante e atual, uma vez que constitui, nas instituições de guarda do patrimônio histórico, um dos assuntos menos discutidos e mais naturalizados no que diz respeito ao cumprimento de metodologias arquivísticas. Na maioria desses ambientes predomina a regra metodológica de separar os documentos iconográficos do restante do acervo do qual fazem parte, para fins de tratamento técnico específico. Essa regra, que tem justificativa a aplicação de procedimentos de conservação diferenciados, estende-se à própria organização do material iconográfico, 
que recebe arranjo e descrição distintos dos aplicados ao restante do arquivo, ocasionando uma perda dos significados daquelas imagens no contexto da produção arquivística $^{6}$ do conjunto. Tradicionalmente vistas como registros autorreferentes, imagens de 'alguma coisa', sem conexão clara com a entidade produtora e responsável pela existência do conjunto, as imagens acabam sendo tratadas por seu conteúdo intrínseco, não sendo percebidas como portadoras de um vínculo arquivístico ${ }^{7}$, que as remetem a outros documentos e, em última instância, as ligam ao próprio titular do arquivo, pessoa física ou jurídica responsável pela produção e acumulação dos documentos.

Podemos apontar pelo menos duas visões, em relação às imagens fotográficas, que colaboram para a situação descrita acima: de um lado, a crença que as imagens são fundamentalmente obras artísticas ou criações pessoais, e que devem ser tratadas uma a uma, como peças de uma coleção; de outro, o caráter de registro objetivo, socialmente atribuído à imagem obtida pelo dispositivo fotográfico devido à capacidade que tem de registrar, com alto grau de semelhança, a aparência das coisas e, sobretudo, de estar conectado a esse referente pela natureza indicial desse tipo de signo visual. ${ }^{8}$

A predominância da busca pelas temáticas veiculadas pelas imagens, do ponto de vista de quem tem nelas o seu objeto de pesquisa, como também de quem as organiza, aponta para o peso do valor de testemunho desse tipo de registro, que está embutido na crença da natureza probatória da fotografia. Nesse caso, a descrição item a item é também um esforço pelo 'resgate' do que de factual a imagem porta.

Na bibliografia sobre arquivos fotográficos, de modo geral, poucos trabalhos se detêm sobre sua natureza e constituição nos domínios público e privado. A maioria gira em torno de regras e métodos de tratamento técnico, ou sobre a conservação e preservação desses registros. Ainda hoje se discute se fotografias deveriam ser ou não consideradas documentos de arquivo, considerando que sua forma de constituição estaria mais próxima dos itens de coleção. No fundo, documentos fotográficos ainda são vistos como 'especiais', tanto na área arquivística, quanto na dos estudos históricos que se servem dela como fonte ou objeto. Na área de história, uma perspectiva relevante e atual sobre a questão das fontes visuais pode ser encontrada em Meneses (2003). Nas reflexões sobre arquivos, o trabalho de Lopez (2000) é sinal de mudança nesse cenário. O autor analisa as especificidades dos documentos imagéticos em arquivos, criticando o tipo de tratamento que os 'condena' ao lugar de itens de coleção e defendendo a ideia da recuperação do caráter arquivístico das imagens, possível a partir da reconstrução do contexto de produção desses documentos, no interior do próprio conjunto. $\mathrm{O}$ trabalho de Lopez representa importante demarcação de espaço para a discussão dos materiais imagéticos em arquivos, diante da aridez de reflexões que caracteriza a área - tanto brasileira quanto estrangeira - e com relação a esse tema especificamente. São raros os trabalhos que apresentam reflexão sobre a natureza arquivística desses materiais a partir de uma perspectiva teórica.

Em que pesem a reconsideração do tratamento conferido ao material iconográfico em geral - e fotográfico em particular - no universo documental, e a centralidade e pertinência que essa tendência teórico-metodológica assume na área de organização de arquivos pessoais e institucionais, privados e públicos -, a questão é ainda bastante desafiadora, entre outras razões pela dificuldade de se estender um mesmo método ou abordagem a 
arquivos de naturezas absolutamente diversas e a tipos documentais bastante heterogêneos entre si. Outros aspectos fundamentais são a natureza e o grau de informações sobre as imagens. Somadas às características de conteúdo (assunto, retratados, autor, local e data), informações sobre as relações dos documentos fotográficos com o titular do arquivo, bem como com os outros documentos do acervo, são importantes chaves para o entendimento do contexto de produção da documentação, na maioria das vezes negligenciadas pelas operações institucionais de tratamento documental.

Nesse sentido, e considerando o momento em que a documentação pessoal de Chagas é objeto de reorganização, gostaríamos de chamar a atenção para algumas questões suscitadas em relação aos significados de algumas imagens no arquivo de Chagas e às operações de sentido acionadas em relação a esse material, num contexto de tratamento técnico de acervos.

\section{As imagens de Carlos Chagas na reorganização de seu arquivo}

O arquivo fotográfico do fundo pessoal Carlos Chagas reúne duzentas fotografias que retratam fatos relacionados majoritariamente à trajetória pública e também a diversos aspectos da vida particular do cientista. Estão presentes, na documentação fotográfica, aspectos de sua vida familiar, de sua atuação à frente do Instituto Oswaldo Cruz (IOC) e do Departamento Nacional de Saúde Pública (DNSP), do período em que passou em Lassance realizando pesquisas sobre a malária e sobre a doença que leva seu nome, de atividades relativas ao ensino médico em Manguinhos e na Faculdade de Medicina do Rio de Janeiro, além de registros que retratam Carlos Chagas em solenidades e eventos diversos.

Uma característica desse material diz respeito à esparsa presença de registros de caráter 'pessoal' da vida do cientista. As imagens que representam essa temática perfazem um total de 41 documentos, sendo 13 retratos (portraits) de Chagas, de seus pais, filhos e esposa; 11 fotografias relativas a diversas caçadas com amigos, atividade que mantinha como hobby; e seis de encontros com a turma de formatura da Faculdade de Medicina, por ocasião de aniversários comemorativos à data. Apenas oito retratam Chagas no ambiente mais pessoal e familiar, quando posa com seus filhos e neta aparentemente no jardim de sua residência. Elas foram reunidas e classificadas junto à documentação textual, no grupo intitulado 'Vida Pessoal', que contém outros tipos documentais como cartas, diplomas, álbuns de recortes de jornais, convites etc. Entre as imagens e os outros tipos documentais sob a mesma classificação não existe nenhum vínculo mais estreito, do ponto de vista de produção ou mesmo de acumulação documental. O critério para a classificação dessas imagens foi a identificação da temática 'familiar' presente nas mesmas, na falta de possibilidade de recuperar, a partir do arquivo, o contexto de produção dessas imagens (Fotos 1 a 5).

Alguns fatores podem ter contribuído para a tímida presença de material mais pessoal. Um deles seria a possível seleção, pela família, das imagens que deveriam seguir para a instituição de guarda da memória de Chagas. É comum, nesses casos, a opinião de que as imagens a serem doadas para a esfera pública sejam as que representem o titular em ação nessa esfera, e não as que dizem respeito à sua figura em atuação mais íntima, estas sim de domínio natural de parentes e familiares próximos. O momento da doação é de valorações 
(tanto de quem doa quanto de quem recebe) das imagens e das possíveis utilidades que elas podem ter ou funções que podem assumir, ao passar do domínio privado para o público.

Outra possibilidade para o entendimento dessa característica vincula-se aos mecanismos de produção fotográfica, à época do cientista. Enquanto as imagens produzidas sobre Chagas - tanto nas instituições pelas quais passou por atuação profissional, quanto pelas empresas jornalísticas responsáveis por divulgar suas ações com repercussão social - eram realizadas de modo sistemático, a produção doméstica de imagens seguia padrões de produção pouco controlados, já que realizada por amadores, na maior parte das vezes. Um olhar atento às autorias presentes nas imagens ou às entrevistas com doadores do acervo ${ }^{9}$, realizadas com o intuito de entender como as imagens surgiram no universo familiar, pode trazer à tona indícios sobre contextos de produção e sentidos das imagens no universo do titular do arquivo. Chamo a atenção para a importância desse entendimento como um dos prérequisitos para a reconstrução de um contexto de produção arquivístico das imagens.

Em contraponto ao conjunto mais esparso de imagens familiares há o de registros concernentes à trajetória profissional de Chagas, o de maior número no acervo. O grupo Gestão de Ciência e Saúde Pública reúne 88 fotografias que registram a atuação do cientista em diversos eventos da agenda típica de um 'gestor', ou 'administrador', função que exerceu por longo período, desde a morte de Oswaldo Cruz em 1917, até seu falecimento em 1934. Fora de Manguinhos, Chagas foi diretor do DNSP de 1920 a 1926 (Fotos 6 a 9). Por outro lado, fotografias de seu período no IOC também encontram-se em outros grupos: Docência, que reúne imagens de sua atuação junto às turmas dos cursos de aplicação do Instituto (três fotos); e Pesquisa, nos subgrupos Doença de Chagas (14 imagens relativas à pesquisa empreendida em Lassance); e Malária (três imagens de sua participação no congresso de malariologia ocorrido em Roma, em 1925). Adiante, o grupo Pesquisa será objeto de discussão.

Voltando ao grupo quantitativamente majoritário - o de 'Gestão de Ciência e Saúde Pública' -, observamos que as imagens que o integram, algumas não identificáveis em termos de referências espaço-temporais ou factuais, foram sendo classificadas de acordo com o que a pesquisa de identificação de eventos e retratados tornava possível. Foram basicamente os dados de conteúdo das imagens, e não dados de contexto documental, os responsáveis por permitir uma inserção das imagens no modelo funcional. Reflexo disso eram os momentos de aflição vividos pela equipe de documentalistas, quando enfrentava o grande desafio de classificar o conjunto de imagens 'sem identificação' que se acumulava. O modelo de classificação funcional, nesse sentido, coloca em evidência a problemática dos documentos fotográficos e suas especificidades.

Um aspecto válido do modelo funcional é tornar 'prismática' a atuação do titular num cargo que, a princípio, aparenta uma sucessão uniforme de eventos. Essa ideia é bastante interessante e nos arquivos ganha especial relevo, pois coloca os próprios documentos como vetores da dinâmica muitas vezes bem mais diversificada do que um simples cargo político-administrativo deixa entrever. Assim, os documentos que tiveram sua origem durante as funções de maior projeção exercidas por Chagas (diretor do IOC e do DNSP) apontam, na verdade, para inúmeras outras atuações exercidas por ele no mesmo período, algumas dessas, desdobramentos do cargo de diretor, enquanto outras possibilitam perceber atividades que Chagas desempenhava em paralelo, como a de pesquisador, que sempre 
manteve, ou ainda a de docente. Por outro lado, a aplicação do modelo funcional representa um desafio metodológico, quando consideramos as características dos registros fotográficos.

Um dos principais problemas é a dificuldade em perceber a 'função original' para as quais esses documentos foram produzidos. Se, de um lado, para a maioria dos documentos tradicionais dos arquivos - geralmente os do gênero textual - é possível realizar a associação documento-função ${ }^{10}$, de outro as fotografias não são documentos auto-explicativos de suas funções, pois não foram produzidas com base em procedimentos controlados e de acordo com regulamentação oficial ou preocupação jurídico/legal. Como não têm essa força elocutória - ao contrário, como registros são bastante irregulares e inconstantes -, apenas mostram uma cena repleta de possibilidades de interpretações. Cabe a quem organiza a documentação buscar informações que auxiliem na compreensão do contexto de produção dos documentos. Nesse sentido, enquanto os documentos tradicionais podem ser pensados segundo uma lógica de 'produção original', conferida em parte pela lógica que os aglutina em séries tipológicas, nas fotografias essa reunião é muitas vezes 'artificial', produzida como consequência das pesquisas de identificação e contexto.

Essas pesquisas são geralmente necessárias devido a uma característica comum aos materiais fotográficos: a falta de informação sobre eles. Como em muitos casos o tempo entre a doação do arquivo e a sua efetiva organização pode ser bastante longo, e os personagens envolvidos na história de guarda do acervo podem ter desaparecido, a busca por essas informações, quando ocorre, é muitas vezes infrutífera. Não havendo esse investimento, a maioria dos métodos de organização de arquivos fotográficos reproduz uma situação na qual os documentos são apresentados como integrantes inertes do que Allan Sekula (1977) apropriadamente chama de inventário de aparências. ${ }^{11}$

No grupo Gestão de Ciência e Saúde Pública, todas as imagens foram classificadas na atividade Participação em Evento e Recepção de Visitantes ${ }^{12}$, com a diferenciação das funções 'diretor do IOC' e 'diretor do IOC e do DNSP' para o período em que acumulou os dois cargos. A partir dessas atividades - participar de eventos e receber visitantes -, as inúmeras imagens são rearticuladas e ganham sentido de coerência no modelo funcional. Como exemplo citamos as várias fotografias de Carlos Chagas nas varandas do Castelo de Manguinhos, com diversos grupos em diferentes momentos (em boa parte não identificados), classificadas em Recepção de Visitantes, apontando para a função maior de Chagas, diretor do IOC, como razão para a sua presença na cena. Embora saibamos que muitos daqueles encontros podem ter ocorrido por motivos relativos às pesquisas que desenvolvia, às atividades docentes, ou até mesmo devido à notoriedade que adquiriu como diretor do DNSP, a falta de identificação não permite precisão na classificação das imagens.

Essas fotos são, em sua grande maioria, produção institucional do IOC, que tinha no fotógrafo J. Pinto um funcionário dedicado a registrar sistematicamente os eventos ocorridos na instituição e a acumular um arquivo fotográfico. ${ }^{13}$ São imagens próximas ao gênero jornalístico do período, apresentando os personagens confundidos com o próprio evento, e procuram cumprir sua finalidade de registro de ocasiões de modo a compor um painel do cotidiano institucional. ${ }^{14}$ Mas esses registros são um dos fios do tecido urdido com outros elementos, que, em face da dispersão documental e do desconhecimento sobre as circunstâncias de produção, contribuem para limitar o potencial das imagens como 
documentos, tanto da história institucional como da história pessoal de Chagas, embora elas possam manter o valor de prova, mesmo que parcial, do evento que retratam.

Particularmente exemplar dessa reflexão sobre a organização da documentação fotográfica é o conjunto que retrata o período em que Chagas passou em Lassance. Sua estada naquela cidade, a partir de junho de 1907, foi ocasionada pela incumbência de combater uma epidemia de malária que afetava as obras de prolongamento, entre Corinto e Pirapora, da Estrada de Ferro Central do Brasil, ícone da modernização brasileira. Chagas, que era médico da Diretoria Geral de Saúde Pública (DGSP) e já chefiara duas outras campanhas contra a doença, foi designado para a missão por Oswaldo Cruz, que chefiava essa Diretoria e conhecia seu trabalho de pesquisa sobre a malária (realizado no Instituto de Manguinhos como tese de doutoramento para a conclusão do curso médico). ${ }^{15}$

Enquanto coordenava as atividades de profilaxia da malária em Lassance, teve início a sucessão de fatos que culminou com o episódio de maior notoriedade em sua trajetória: a descoberta de uma nova enfermidade tropical. As imagens que representam esse período estão todas classificadas no Grupo Pesquisa, subgrupo Doença de Chagas, e relacionadas à atividade Registros Visuais em Trabalho de Campo. Até mesmo as que mostram Chagas com a turma de engenheiros encarregados das obras da ferrovia, chefiados por Cornélio Homem Cantarino Mota, com os quais Chagas - e Belisário Penna, também médico da DGSP - mantinha relações em razão das atividades de combate à malária, foram classificadas no subgrupo Doença de Chagas (Foto 10). Sobre a Foto 10 em particular, vale destacar que, embora a ela não tenha sido atribuída uma data precisa, pode-se afirmar que foi tirada antes da descoberta da doença (abril de 1909), porque a estação de Lassance foi inaugurada em fevereiro de 1908, e a imagem refere-se a um evento acontecido durante os estudos para as obras de construção da ferrovia (e a razão para a presença de Chagas ali era a sua atividade de profilaxia da malária).

Segundo relato do próprio Carlos Chagas, mais de um ano se passou entre sua chegada à região e o início dos estudos que resultariam na descoberta da doença de Chagas. Nesse relato, menciona o cientista uma viagem a Pirapora (MG) com Belisário, na qual, durante pernoite no acampamento dos engenheiros encarregados dos estudos da linha férrea, conheceram o barbeiro, mostrado pelo próprio Cantarino Mota. ${ }^{16}$

O relato do engenheiro (Mota, 1954), bem posterior ao de Chagas, menciona essa viagem como sendo o momento em que Chagas tomou conhecimento dos barbeiros (inclusive na cafua mostrada pela imagem), ponto inicial das pesquisas que o levariam à descoberta da doença.

Somada às versões sobre o fato, há a dificuldade de datação precisa (dessa e de outras imagens), que dificulta o entendimento da razão de sua produção. No entanto, a questão principal não é estabelecer se a imagem em questão relaciona-se com os eventos relativos à pesquisa com malária, ou se concerne ao início dos estudos que levariam Chagas a descobrir uma enfermidade. Trata-se, antes, de uma imagem cujo sentido deve ser buscado a partir da aceitação da existência de um campo 'fronteiriço' entre esses episódios - e nesse sentido ela é emblemática dessa superposição de sentidos.

Além da foto em questão, cabe salientar que há outras, do período em Lassance, que não abordam necessariamente a doença de Chagas, a exemplo das imagens da própria ferrovia ou temas relacionados, como a estação, o prédio da Estrada de Ferro Central do 
Brasil, uma vista da cidade cujo 'recorte' privilegia o registro da ferrovia e arredores, as instalações onde ficou hospedado Carlos Chagas (Fotos 11 e 12). Mas essas imagens, ao lado de outras cujo vínculo com a descoberta da doença é evidente (Fotos 13 e 14), são associadas ao momento mais significativo, que de certa forma as une e identifica: o período em Lassance e as consequências dele na vida de Chagas. Assim, todas elas foram sendo investidas, com o tempo, do sentido de 'expressão documental' de Chagas em Lassance, ou seja, de Chagas no local onde descobriu a tripanossomíase. Nesse sentido, a própria cidade foi ressignificada: de povoado em que se construía uma estação ferroviária a local da descoberta da doença de Chagas. ${ }^{17}$

Essas imagens e a exposição das tramas nas quais seus sentidos vão sendo tecidos no tempo nos ajudam a pensar sobre um aspecto interessante (e exemplar) de um fenômeno recorrente nas organizações dos arquivos. Diz respeito às ressignificações dos documentos em geral - e das imagens de forma privilegiada - a partir do olhar de quem organiza, considerando os sentidos conferidos à atuação do titular ao longo de sua vida e consolidados numa visão a posteriori.

A organização de um arquivo pessoal contribui para a construção de uma memória sobre o responsável pela existência daqueles documentos, e nos processos de tratamento técnico pelos quais a documentação é submetida existem múltiplas intervenções que afetam a configuração do arquivo. Luciana Heymann (1997) destaca a responsabilidade dos profissionais que lidam com a organização de acervos, seja na constituição dos corpora documentais que têm em mãos, ou no processo de trabalho com os arquivos. Ela ressalta a sutileza e a abrangência dessa interferência, ao analisar o papel do documentalista na 'produção' do arquivo como fonte. Ainda segundo Heymann (p.49),

somada à intervenção de herdeiros e secretários, a [subjetividade] do arquivista compõe um plano de subjetividades intermediárias, entre aquela que norteou a acumulação do titular e aquela do pesquisador que vai construir o discurso histórico/científico a partir dos 'fragmentos' que compõem o arquivo. No seu caso, no entanto, trata-se de uma subjetividade submetida à pragmática que orienta o trabalho arquivístico, mais silenciosa mas nem por isso menos efetiva. Melhor seria falar de um plano invisível de subjetividade e intervenção, na medida em que não se revela, ocupando um espaço de sombra. É ofuscado, de um lado, pela materialidade do arquivo, indissociavelmente vinculado ao titular de quem empresta o nome e, de outro, pela obra produzida a partir das fontes, cuja autoria é igualmente reconhecida. ${ }^{18}$

No caso de um personagem como Chagas, trata-se de uma trajetória profundamente marcada por um episódio singular - a descoberta da doença que o consagraria - e que, por isso mesmo, é apresentada, nas narrativas históricas e memorialísticas, como sendo inevitavelmente referenciada a esse feito, tanto no período que o antecedeu como no que lhe foi subsequente. Este marco orienta, mesmo que subliminarmente, as decisões tomadas ao longo do tratamento da documentação.

Em estudo sobre a construção da memória através de um acervo pessoal, Bertonha (2007) utiliza uma noção que pode ajudar a compreender esse aspecto na organização do arquivo de Chagas. Analisando o arquivo de Plínio Salgado (1895-1975), o autor chama a atenção para o que denomina tempo referencial na vida de pessoas, em que um fato ou período marcante ou extraordinário passa a servir de marco a partir do qual essa trajetória 
é reconhecida, compreendida ou mesmo justificada. Segundo ele, "para muitas pessoas, existe o que chamo de 'tempo referencial', aquele em que a pessoa vive o seu momentochave, especial e a partir do qual todas as suas experiências posteriores são comparadas ou avaliadas" (p.5). No caso em questão, o marco na trajetória de Plínio Salgado refere-se à sua participação na cena política nacional nos anos de 1930, como fundador da Ação Integralista Brasileira em 1932 e líder do movimento integralista nacional.

Bertonha (2007) analisa o papel que o próprio titular exerce sobre seu arquivo, na dinâmica de produção e acumulação de documentos, para transformá-lo em 'legado' que justifique ou explique sua vida. Mas acredito que suas ideias podem ser úteis na problematização do papel dos profissionais envolvidos na organização a posteriori de um arquivo como o de Carlos Chagas. Hoje, as imagens sobre o período passado em Lassance são compreendidas como uma sucessão de momentos que culminariam no fato mais marcante da vida do cientista e que lhe conferiu sentido. Tais imagens são apresentadas, na sequência descritiva do inventário, como um encadeamento narrativo acerca da "pesquisa em doença de Chagas", mesmo que algumas delas, pelas informações colhidas, estejam mais diretamente associadas às razões primeiras que o levaram à região, o trabalho de profilaxia de malária. Sobre a pesquisa em malária propriamente dita, conforme já mencionado, a classificação do arquivo reuniu três fotos, todas acerca de sua participação num congresso de malariologia realizado em Roma, em 1925. O conjunto de fotos relativo à fase em Lassance foi, assim, reinterpretado na organização posterior do arquivo, a partir da importância e do valor simbólico que os desdobramentos dos fatos ali vividos por Chagas imprimiram à sua trajetória.

\section{Considerações finais}

À guisa de conclusão, sublinho que a abordagem contextual dos arquivos é uma boa conduta a ser adotada na organização de qualquer acervo. Ela objetiva ultrapassar a força dos conteúdos dos documentos e mover-se em direção às razões e circunstâncias de sua existência e os sentidos de sua produção. Somada a essa atitude metodológica, a percepção de que um arquivo nunca constitui uma unidade, um reflexo da vida de quem o produziu deve nortear o trabalho, tanto dos documentalistas quanto dos pesquisadores que se servem dos arquivos. Nesse sentido, cabe aos organizadores valorizar as informações 'de bastidores' do trabalho arquivístico, aquelas que advêm de suas pesquisas sobre o acervo e que, ao final do tratamento técnico, devem sair de seus rascunhos de trabalho para integrar o instrumento de pesquisa.

Na forma de textos introdutórios ou analíticos, convém mencionar lacunas, incoerências, aspectos de fragmentação que toda documentação apresenta. Além disso, a descrição da história da constituição do acervo (com os vários atores porventura envolvidos, além do titular formal do arquivo), a observação quanto às opções que orientaram o trabalho arquivístico e a escolha por determinado arranjo ou classificação, em detrimento de outros, por exemplo, são aspectos do trabalho que tornam explícitas, para qualquer interessado na documentação, as opções tomadas durante a organização. Essas informações servem como contraponto ao caráter objetivo dos instrumentos de pesquisa e nos permitem um olhar mais abrangente e qualificado em direção aos arquivos. 


\section{AGRADECIMENTOS}

A Francisco dos Santos Lourenço, pesquisador do Departamento de Arquivo e Documentação da Casa de Oswaldo Cruz, pelas informações a respeito da história arquivística dos documentos da família Chagas, a partir das quais pude reconstruir, mesmo que parcialmente, o percurso percorrido pelo arquivo na sua transferência da esfera privada para a esfera pública.

\section{NOTAS}

${ }^{1}$ Integraram essa equipe Renata Silva Borges (coordenação geral), Danielle Cristina dos Santos Barreto, Marcela Virgínia Thimóteo da Silva, Francisco dos Santos Lourenço, Aline Lopes de Lacerda (coordenação da organização do material iconográfico) e Cleice de Souza Menezes.

${ }^{2}$ Exemplos dos usos da documentação que Chagas Filho acumulou são a exposição Un Aspect Inconnu du Brésil: L'Oeuvre de Carlos Chagas (1879-1934), exibida no Palais de la Découverte, em Paris (1955), e a produção de uma biografia de seu pai (Chagas Filho, 1993).

${ }^{3}$ Denomina-se titular de um arquivo privado pessoal o indivíduo responsável pela produção e/ou acumulação do conjunto documental.

${ }^{4}$ A antiga organização intitulava o conjunto da documentação como Fundo Família Chagas. Com a reorganização foram constituídos os arquivos pessoais de Carlos Chagas, Carlos Chagas Filho e Evandro Chagas.

${ }^{5}$ Sobre o assunto, ver Santos, 2002. Ver também os relatos de como foi processada a organização do arquivo de Frederico Simões Barbosa, primeira iniciativa do gênero na Casa de Oswaldo Cruz (Santos et al., 2007; Santos, Lourenço, 2007).

${ }^{6} \mathrm{O}$ contexto de produção arquivística, atualmente uma noção importante para a teoria e metodologia dos arquivos, diz respeito ao conjunto de informações sobre a gênese do documento na sua relação com a função pela qual foi formulado e produzido. Ele pode coadunar-se ou não com a temática que o documento veicula. Para a arquivística contemporânea, é o contexto de produção, e não mais os temas ou assuntos, o principal alvo a ser atingido pela organização, o único capaz de aproximar a documentação de seus sentidos mais 'originais'. As buscas, interpretações, pesquisas são momentos posteriores a essa etapa, e a crítica incide sobre certas classificações de arquivos que se utilizam da perspectiva da pesquisa (geralmente baseada nos assuntos) como bússola para organizar os documentos. Ver, a esse respeito, Camargo, Goulart, 2007.

${ }^{7} \mathrm{O}$ conceito de vínculo arquivístico (archival bond) é muito caro à teoria clássica arquivística. Significa que os arquivos são necessariamente compostos por documentos e suas complexas relações. Por essa razão, esse vínculo torna-se componente essencial do arquivo. Ele é a relação que liga cada documento do arquivo ao documento antecedente e subsequente, bem como a todos que tiveram participação numa mesma atividade exercida pelo titular do arquivo. O vínculo é originário (nasce com o documento), necessário (presente em cada um deles) e determinado (caracterizado pela finalidade do arquivo). Ver, a esse respeito, Macneil, 2000.

${ }^{8}$ Sobre a natureza indicial do signo fotográfico, ver Dubois, 1994.

${ }^{9}$ Diante dos anos de trabalho com acervos fotográficos, e considerando os estudos sobre essa parcela constituinte dos acervos históricos, defendo fortemente a ideia de que, nas instituições de guarda desses materiais, houvesse a iniciativa de se constituir, em paralelo, um programa de história oral sobre os arquivos. Entrevistas com os próprios titulares quando ainda vivos, ou com atores diretamente envolvidos na história da documentação são importantes fontes de informação para os trabalhos de organização documental e, como consequência, para os pesquisadores da documentação em geral. Chalfen (1998) apresenta trabalho instigante sobre a metodologia de história oral como instrumento no auxílio para a pesquisa sobre produção familiar de imagens.

${ }^{10}$ Existem diversos documentos típicos da administração, como atas, relatórios, certidões, diplomas e memorandos, que trazem em sua configuração mesma e de forma muito explícita a função para a qual foram gerados. Além disso, como são produzidos em série, a própria sequência documental aponta para o caráter rotineiro de sua produção, ligado a uma finalidade prática que, via de regra, é consequência da necessidade de cumprimento de uma função. 
${ }^{11}$ Em seu texto, Sekula (1997) - artista, escritor e crítico fotográfico americano - faz uma avaliação um tanto ácida, mas nem por isso menos oportuna, sobre o que denomina despolitização do significado fotográfico e a influência do modelo serial dos arquivos sobre o caráter de 'verdade' da imagem fotográfica, contribuindo para a naturalização do que é, como as imagens, construído culturalmente. Essa naturalização se reflete nos usos posteriores desses materiais, como discursos históricos ou estéticos/ artísticos.

${ }^{12}$ Sublinho o fato de que essa atividade foi especialmente criada, no quadro de classificação, para abrigar todo o conjunto de imagens, enquanto o restante da documentação textual foi dividido em atividades específicas.

${ }^{13}$ Sobre o papel que a fotografia desempenhou no processo de institucionalização e legitimação do IOC durante a primeira metade do século XX, ver Mello, Lacerda, 2005.

${ }^{14}$ Observo que esse gênero de imagens não representa, no arquivo institucional do IOC, o padrão dominante, mas sim um dos tipos de documentos fotográficos produzidos à época, ao lado de imagens de doentes, fotomicrografias e outros tipos de fotografias provenientes das atividades científicas do IOC.

${ }^{15}$ Sobre a trajetória de Carlos Chagas e o período em Lassance, ver Chagas Filho, 1993, e Kropf, Hochman, 2007. Sobre a atuação de Chagas em campanhas contra a malária, ver Benchimol, Silva, 2008. Sobre o processo da descoberta da doença, ver Kropf, 2006, e Kropf, Sá, em artigo neste volume.

16 Trecho do relato de Carlos Chagas (1922, citado em Chagas Filho, 1993, p.88). "Mais de um ano permanecemos naquela zona, sem que houvéssemos sabido da existência ali, nas choupanas dos regionais, de um inseto hematófago, denominado vulgarmente barbeiro, chupão ou chupança". E ainda: "Numa viagem a Pirapora, e quando pernoitávamos, o Dr. Belisario Penna e eu, no acampamento de engenheiros, encarregados dos estudos da linha ferrea, conhecemos o barbeiro, que nos foi mostrado pelo Dr. Cantarino Motta, chefe da commissão de engenheiros".

${ }^{17}$ Destaque-se o fato de que são poucos os trabalhos que mencionam que o povoado de Lassance antes da inauguração da estação ferroviária, em fevereiro de 1908. A localidade chamava-se São Gonçalo das Tabocas e sua nova denominação deve-se às obras da ferrovia, pois era o nome do chefe das obras de construção da estação (Ernesto Lassance Cunha). Com a descoberta de Carlos Chagas, a cidade passou a associar-se permanentemente a esse fato.

${ }^{18}$ A análise dos processos a partir dos quais os arquivos pessoais são 'produzidos', desde o estágio de acumulação até a sua configuração final, como fonte disponível para pesquisa pode ser conferida em Heymann, 1997.

\section{REFERÊNCIAS}

BENCHIMOL, Jaime Larry; SILVA, André Felipe Cândido da.

Ferrovias, doenças e medicina tropical no Brasil da Primeira República. História, Ciências, Saúde, Manguinhos, Rio de Janeiro, v.15, n.3, p.719-762. 2008.

BERTONHA, João Fábio.

A construção da memória através de um acervo pessoal: o caso do fundo Plínio Salgado em Rio Claro (SP). Patrimônio e Memória, Assis, v.3, n.1, p.1-9. Disponível em: http://www.assis. unesp.br/cedap/patrimonio_e_memoria/ patrimonio_e_memoria_v3.n1/joao_fabio_ bertonha.pdf. Acesso em: 7 abr. 2009. 2007.

CAMARGO, Ana Maria de Almeida; GOULART, Silvana.

Tempo e circunstância: a abordagem contextual dos arquivos pessoais - procedimentos metodológicos adotados na organização dos documentos de Fernando Henrique Cardoso.
São Paulo: Instituto Fernando Henrique Cardoso. 2007.

CHAGAS, Carlos.

Descoberta do Trypanosoma cruzi e verificação da tripanossomíase americana: retrospecto histórico. Memórias do Instituto Oswaldo Cruz, Rio de Janeiro, v.15, n.1, p.67-76. 1922.

CHAGAS FILHO, Carlos.

Meu pai. Rio de Janeiro: Casa de Oswaldo Cruz. 1993.

CHALFEN, Richard.

Interpreting family photography as pictorial communication. In: Prosser, Jon (Ed.).

Image-based research: a sourcebook for qualitative researchers. London: Routledge. p.214-234. 1998.

DUBOIS, Philipe.

$O$ ato fotográfico e outros ensaios. Campinas: Papirus. 1994. 
HEYMANN, Luciana Quillet. Indivíduo, memória e resíduo histórico: uma reflexão sobre arquivos pessoais e o caso de Felinto Muller. Estudos Históricos, Rio de Janeiro, v.10, n.19, p.41-66. 1997.

KROPF, Simone Petraglia.

Doença de Chagas, doença do Brasil: ciência, saúde e nação (1909-1962). Tese (Doutorado) Instituto de Ciências Humanas e Filosofia, Universidade Federal Fluminense, Rio de Janeiro. 2006.

KROPF, Simone Petraglia.; HOCHMAN, Gilberto.

Carlos Ribeiro Justiniano Chagas. In: Bynum, William F.; Bynum, Helen (Org.). Dictionary of medical biography. v.1. Connecticut: Greenwood. p.320-325. 2007.

LOPEZ, André Porto Ancona.

As razões e os sentidos: finalidades da produção documental e interpretação de conteúdos na organização arquivística de documentos imagéticos. Tese (Doutorado) - Faculdade de Filosofia, Letras e Ciências Humanas, Universidade de São Paulo, São Paulo. 2000.

MACNEIL, Heather.

Creating and maintaining trustworthy records in eletronic systems: archival diplomatic methods. In: MacNeil, Heather. Trusting records: legal, historical and diplomatic perspectives. Dordrecht: Kluwer Academic Publishers. p.86-112. (The Archivist's Library, 1). 2000.

MELLO, Maria Teresa Villela Bandeira de; LACERDA, Aline Lopes de.

Imágenes de la salud pública: la institucionalización del Instituto Oswaldo Cruz en Brasil. Dynamis, Granada, n.25, p.179-198. 2005.
MENESES, Ulpiano T. Bezerra de.

Fontes visuais, cultura visual, história visual. Balanço provisório, propostas cautelares. Revista Brasileira de História, São Paulo, v.23, n. 45 , p.11-36. 2003.

MOTA, Cornélio Homem Cantarino. [Depoimento]. Singra, Rio de Janeiro, v.7, n.10. Integra o Arquivo Cantarino Mota, Casa de Oswaldo Cruz/Fiocruz. 1954.

SANTOS, Paulo Roberto Elian dos. Entre o laboratório, o campo e outros lugares: gênese documental e tratamento técnico em arquivos de cientistas. Dissertação (Mestrado) Faculdade de Filosofia, Letras e Ciências Humanas, Universidade de São Paulo, São Paulo, 2002.

SANTOS, Paulo Roberto Elian dos et al. Saúde pública e ações comunitárias no arquivo Frederico Simões Barbosa. Patrimônio e Memória, Assis, v.3, n.1, p.1-11. Disponível em: http://www.assis.unesp.br/cedap/patrimonio_ e_memoria/patrimonio_e_memoria_v3.n1/ francisco_lourenco.pdf. Acesso em: 13 abr. 2009. maio 2007.

SANTOS, Paulo Roberto Elian dos; LOURENÇO, Francisco dos Santos. Introdução. In: Fundação Oswaldo Cruz. Casa de Oswaldo Cruz. Fundo Frederico Simões Barbosa: inventário. Rio de Janeiro: Fiocruz. p.17-22. 2007.

ROUILLÉ, André.

La photographie. Paris: Éditions Gallimard. 2005.

SEKULA, Allan.

Reading an archive. In: Wallis, Brian (Ed.). Blasted allegories: an anthology of writings by contemporary artists. New York: The New Museum of Contemporary Art. p.114-127. 1997.

\section{$\rightarrow \rightarrow \rightarrow<<<$}




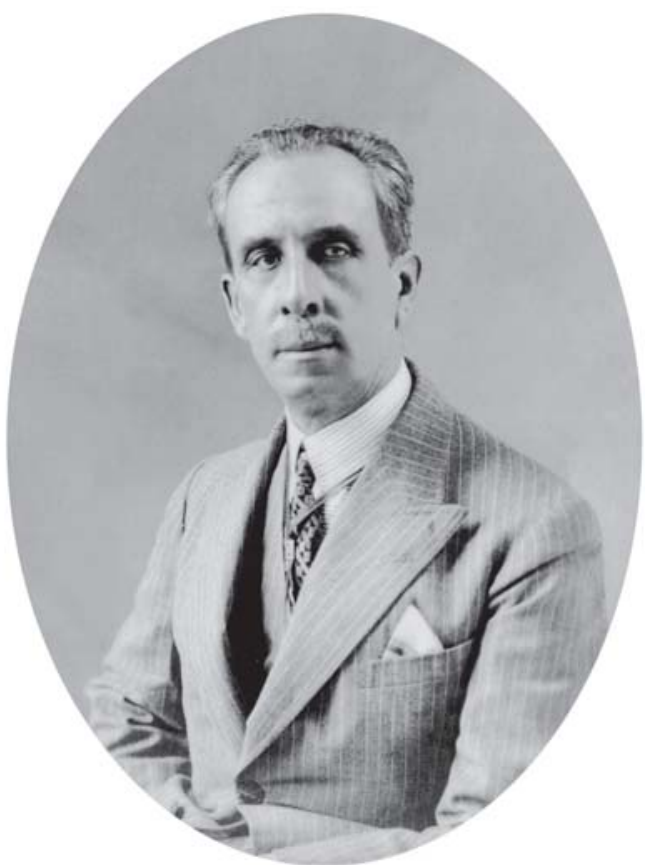

Foto 1: Retrato de Carlos Chagas

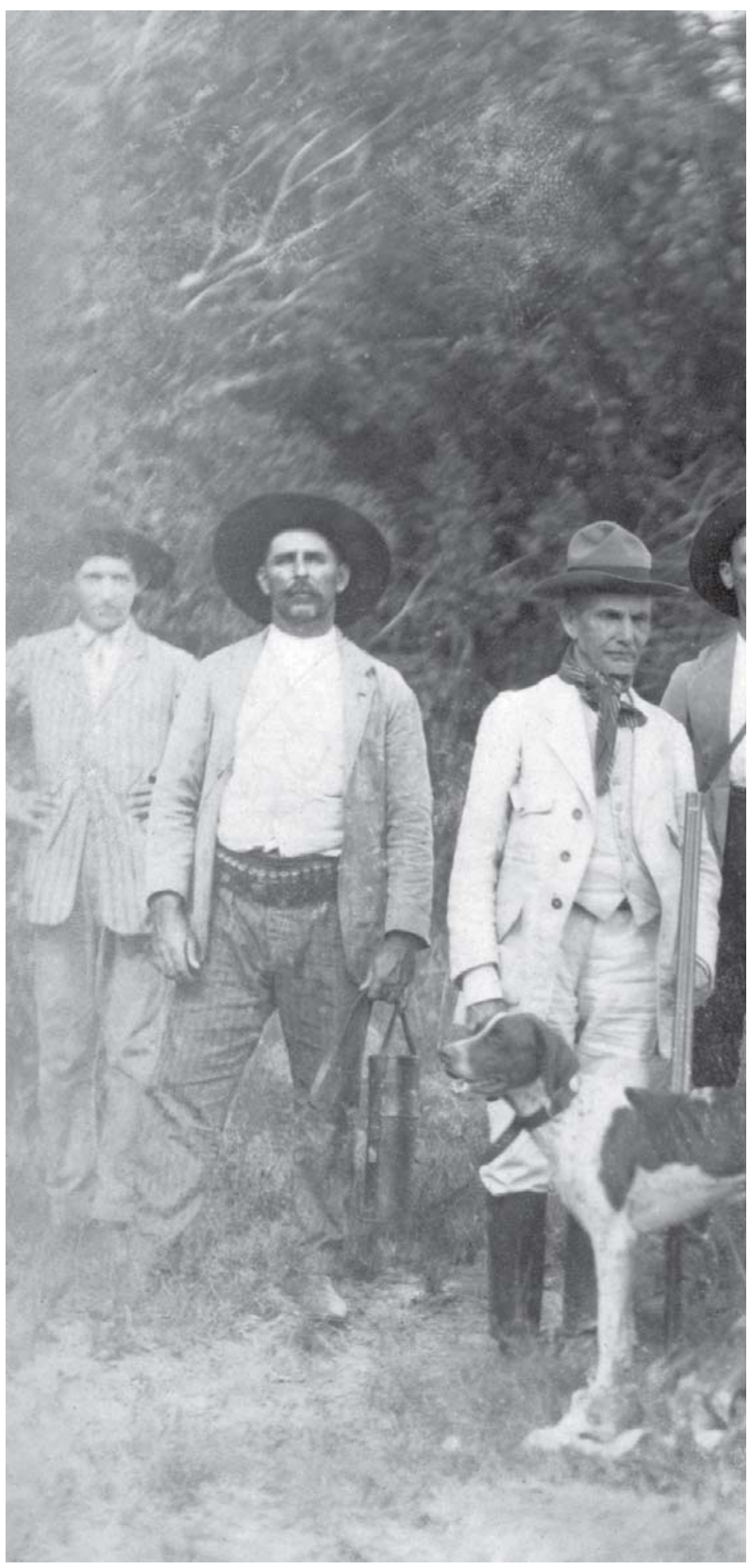

Foto 2: Carlos Chagas (da direita, o primeiro) durante uma caçada ao lado do deputado mineiro João Penido (à direita de Chagas). [1913?] 


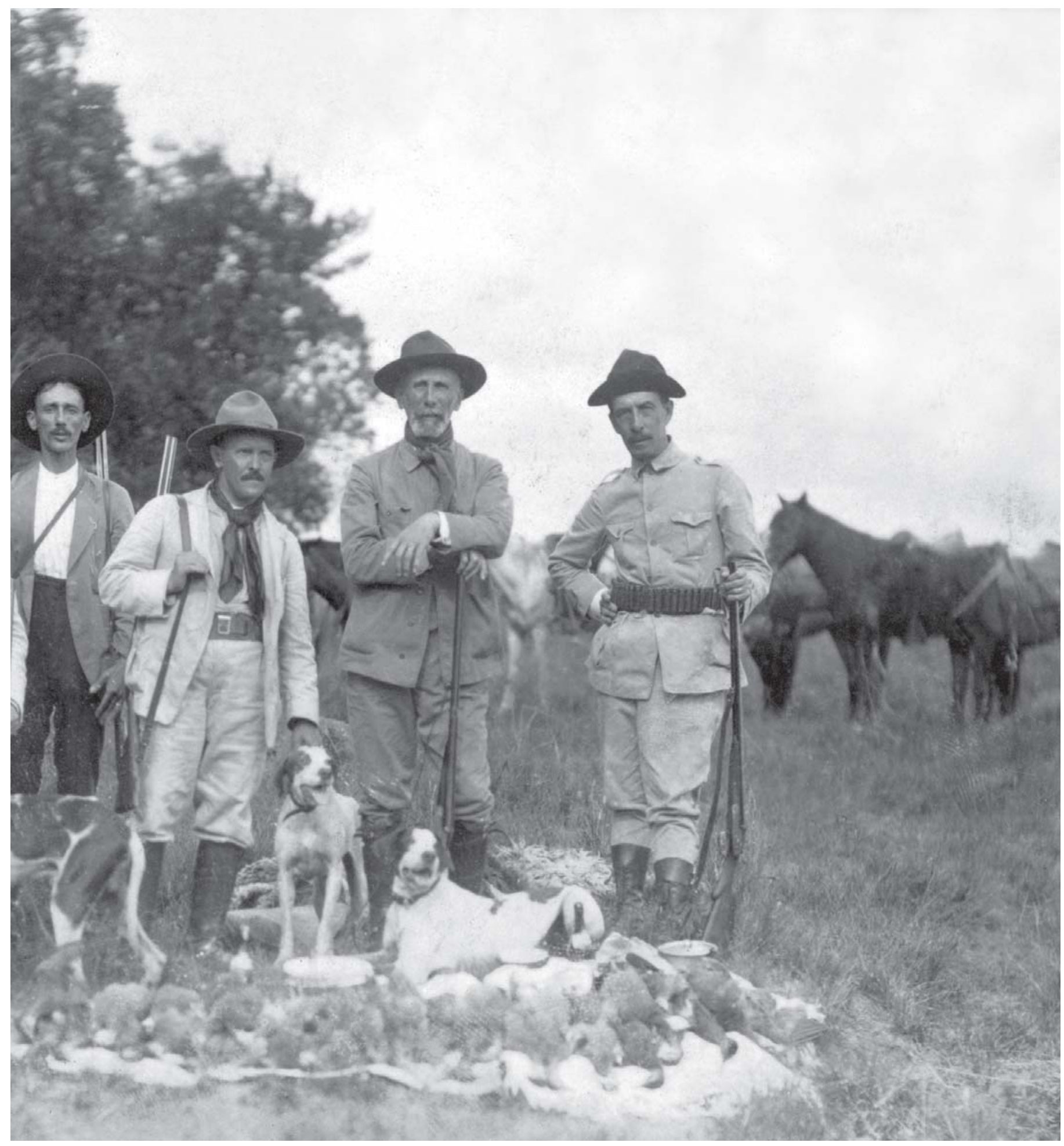




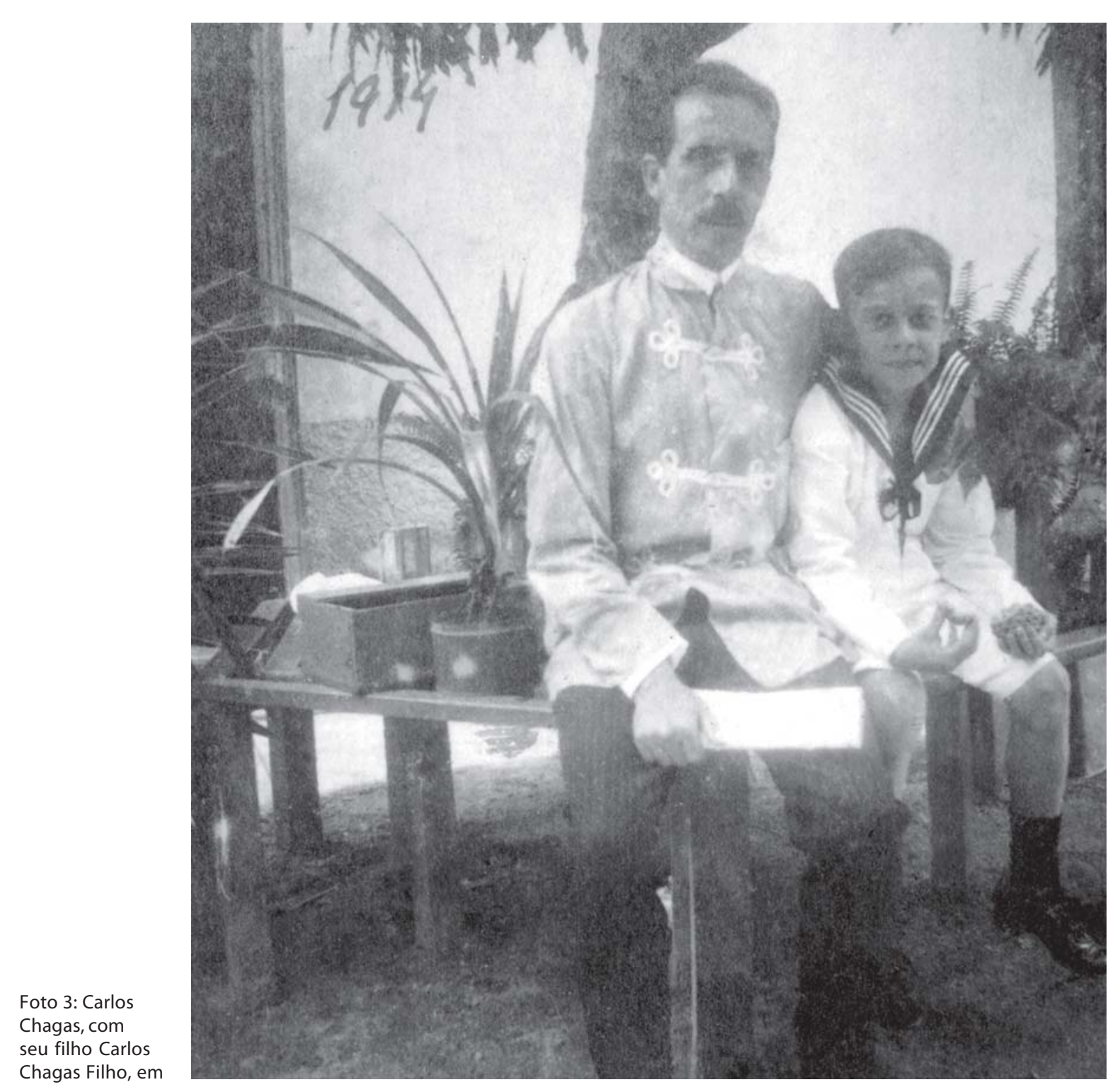
1914.

Foto 4: Carlos

Chagas com sua

neta Tatiana, filha

de Evandro

Chagas. [1930?]

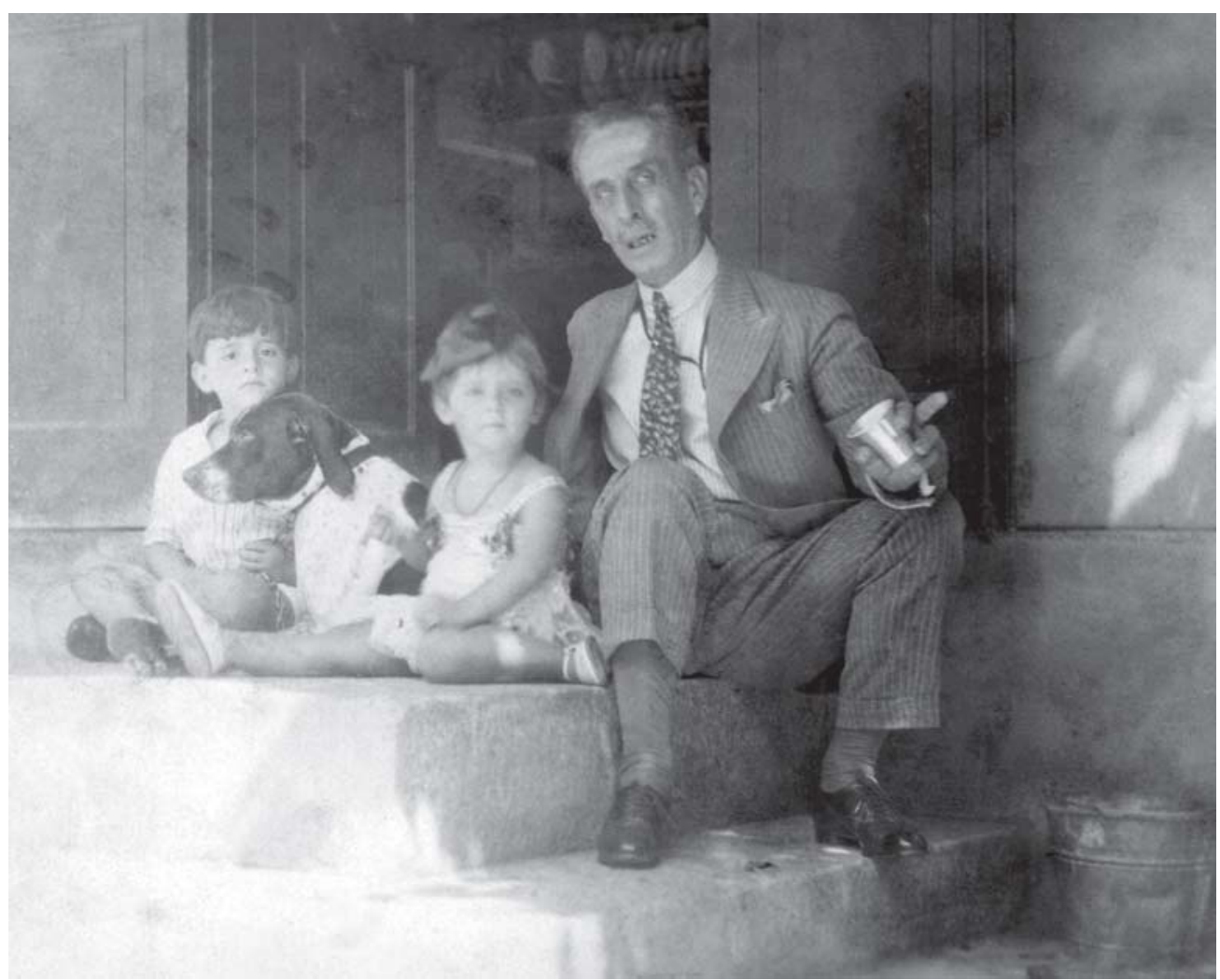




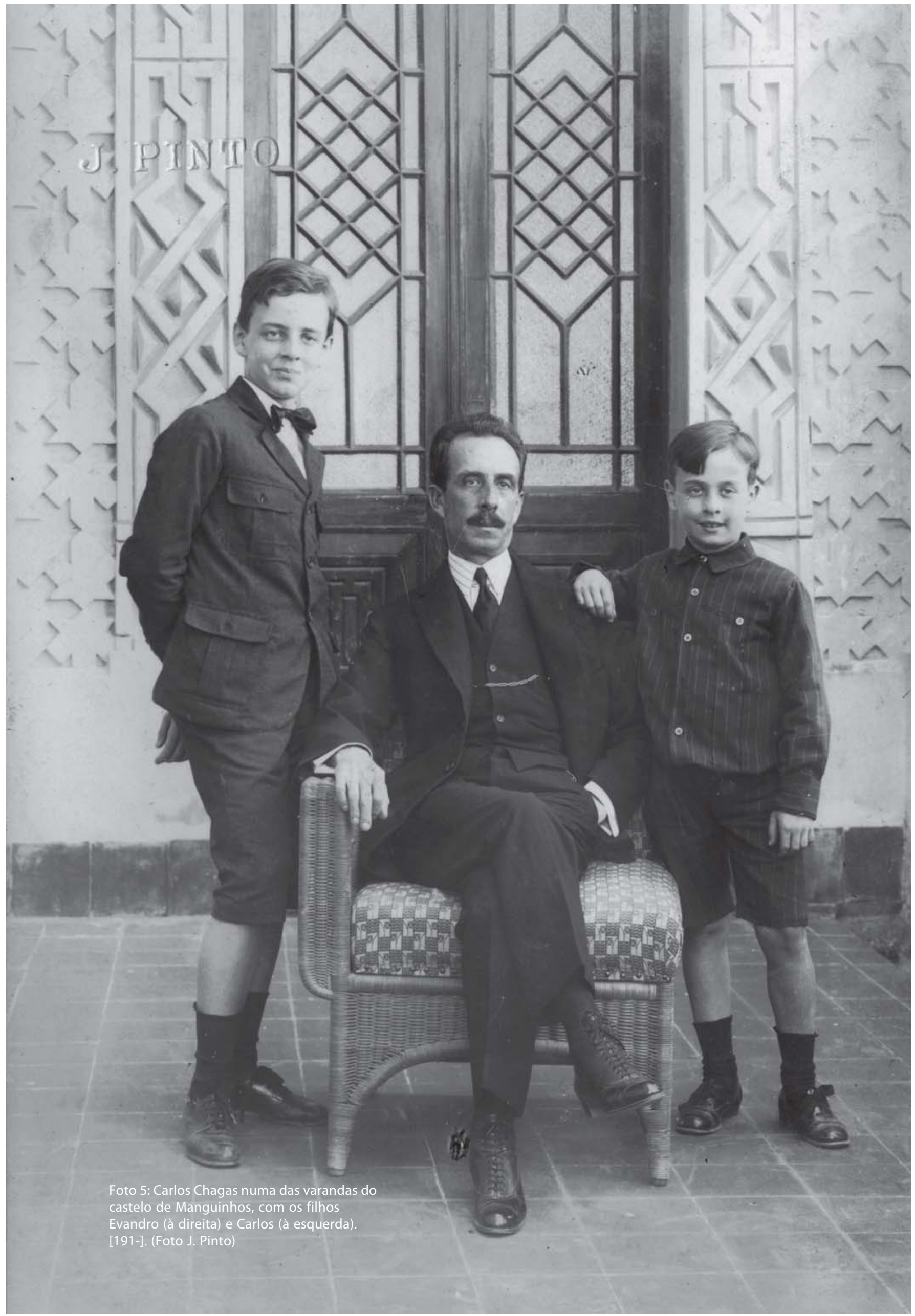




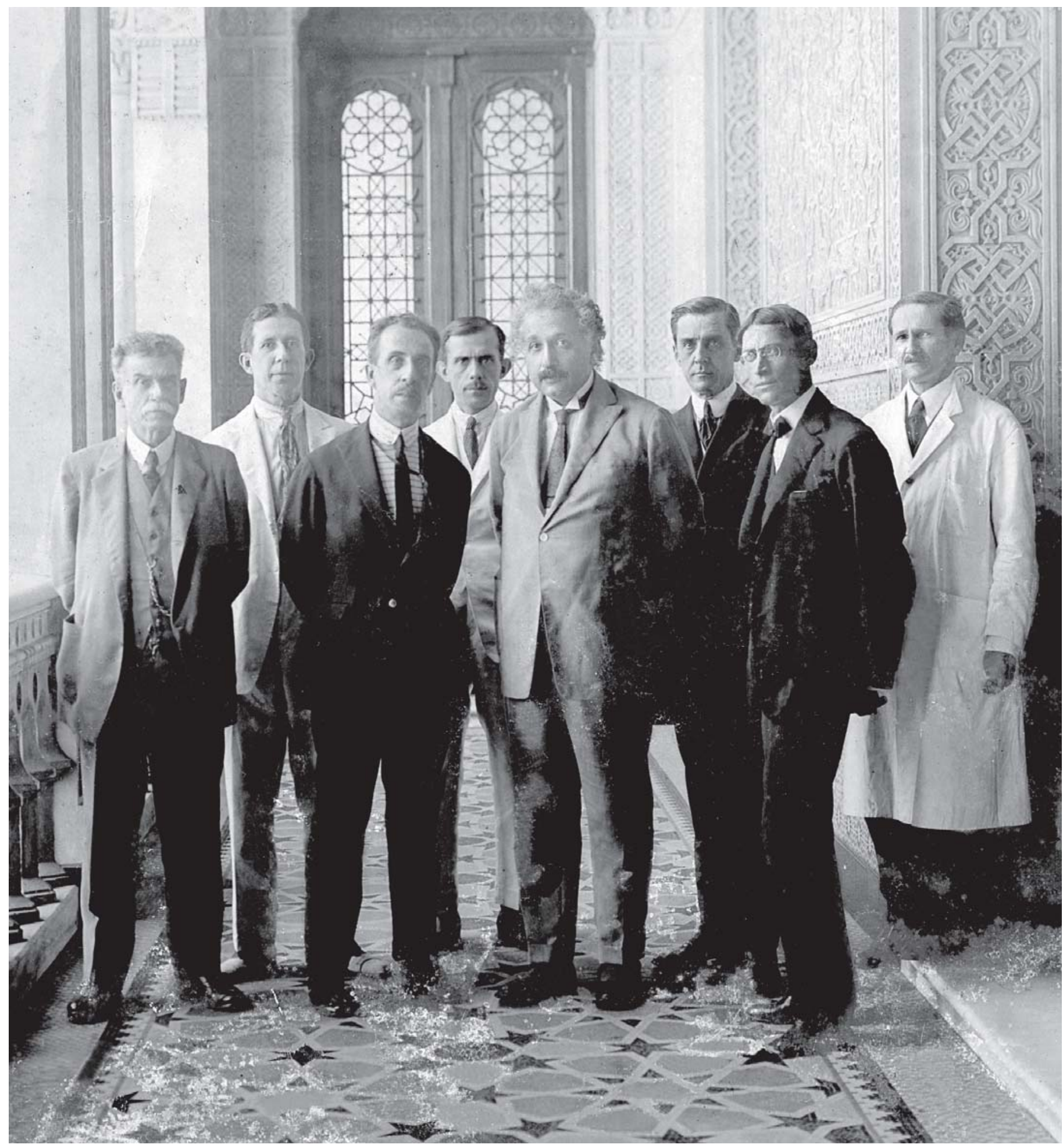

Foto 6: Carlos Chagas recebe a visita do cientista Albert Einstein nas instalações do Instituto Oswaldo Cruz na presença de pesquisadores como Alcides Godoy, Astrogildo Machado, Carneiro Felippe e Leocádio Chaves. 9 maio 1925. 

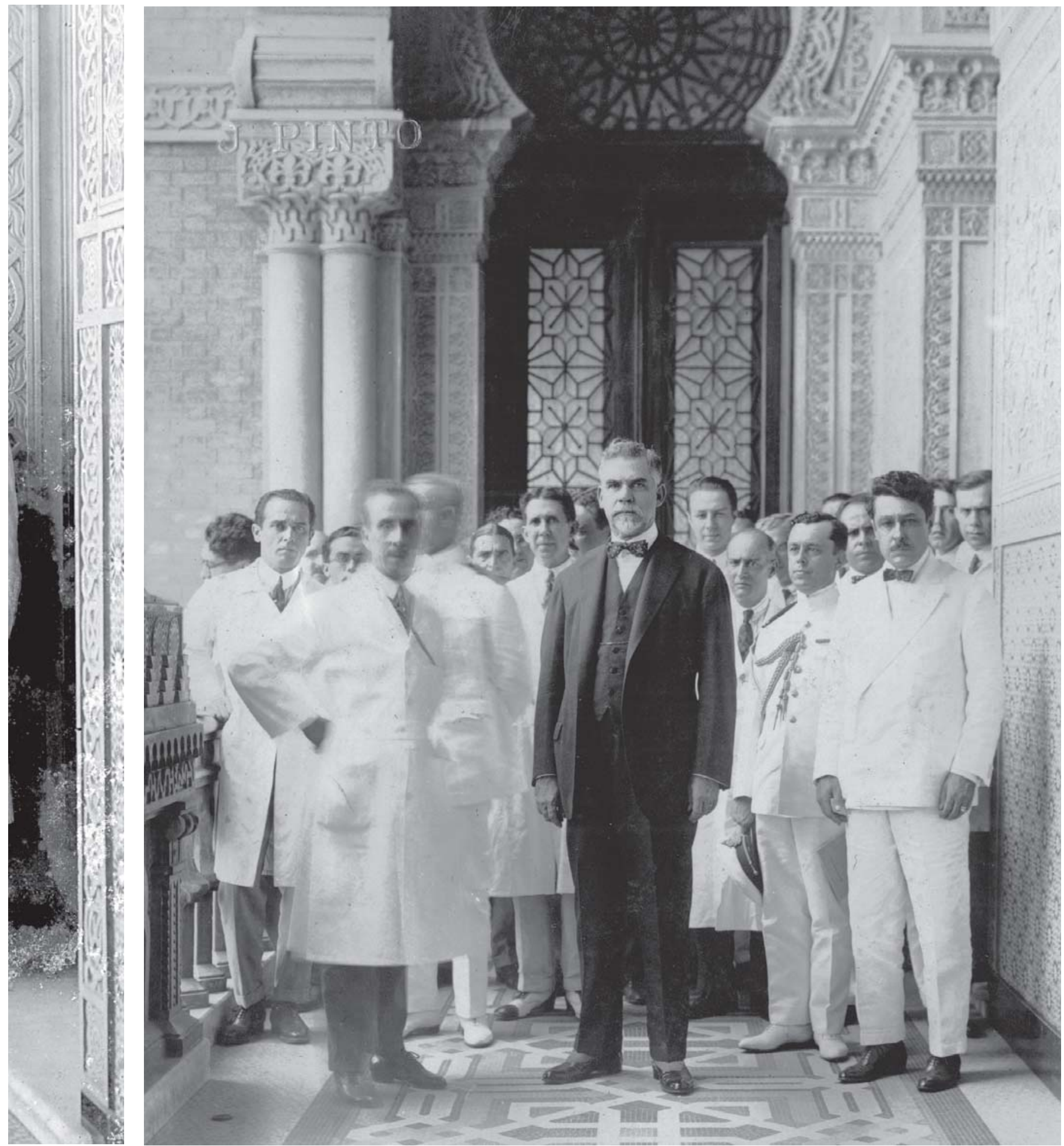

Foto 7: Carlos Chagas recebe o presidente da República, Washington Luiz, durante visita às instalações do IOC. Presentes à ocasião, Alcides Godoy, Antônio Cardoso Fontes, o ministro Augusto Viana, César Pinto, entre outros. 1926. 


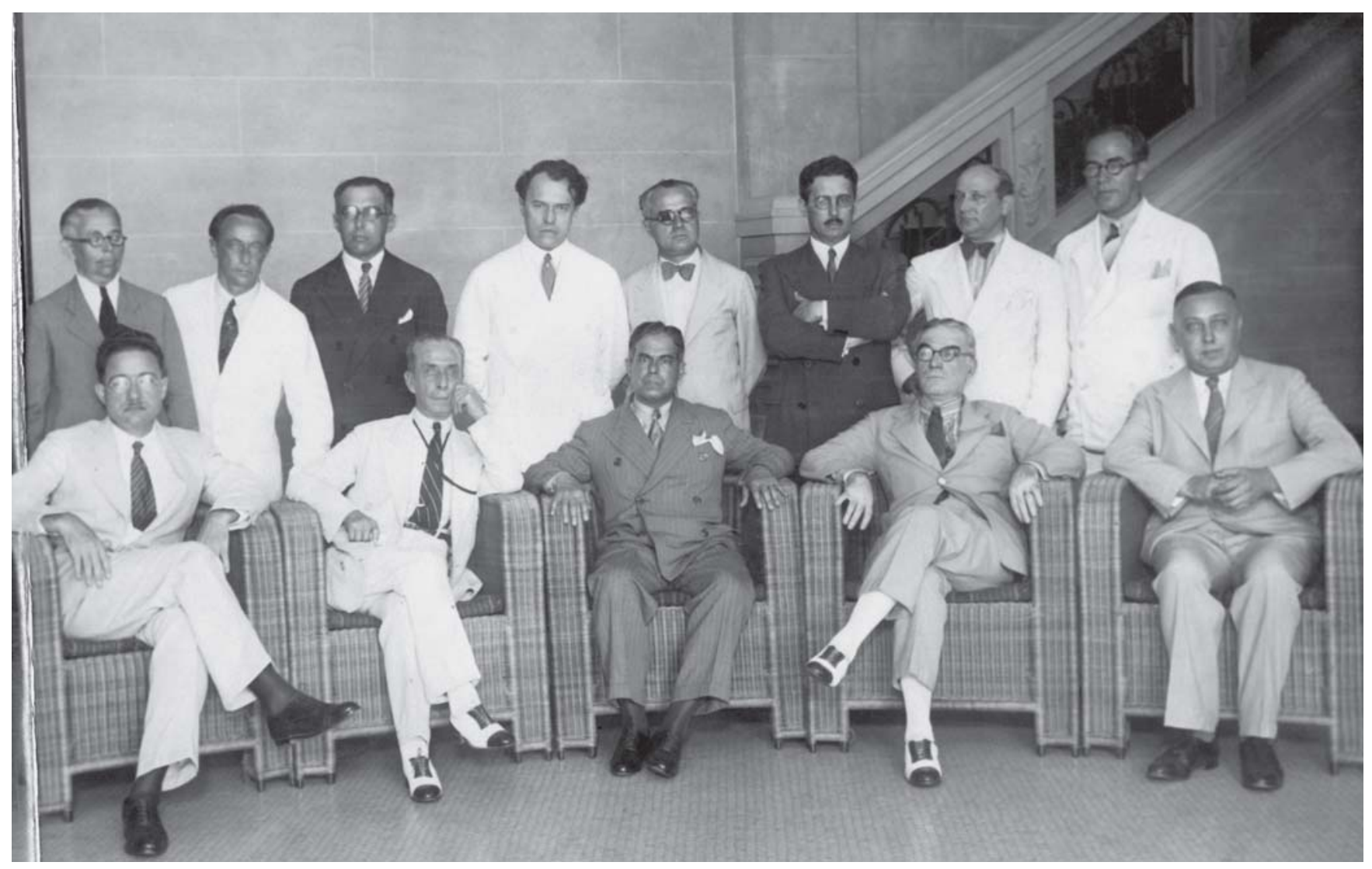

Foto 8: Da esquerda, sentados, Carlos Chagas (o segundo) reunido com Fred Lower Soper (responsável a partir de 1930 pelas ações da Fundação Rockefeller nas campanhas de combate à febre amarela no país - o primeiro), Raul de Almeida Magalhães (o quarto). De pé, Mário Pinotti (o quarto), entre outros. As razões do encontro não foram identificadas. [entre 1930 e 1934]

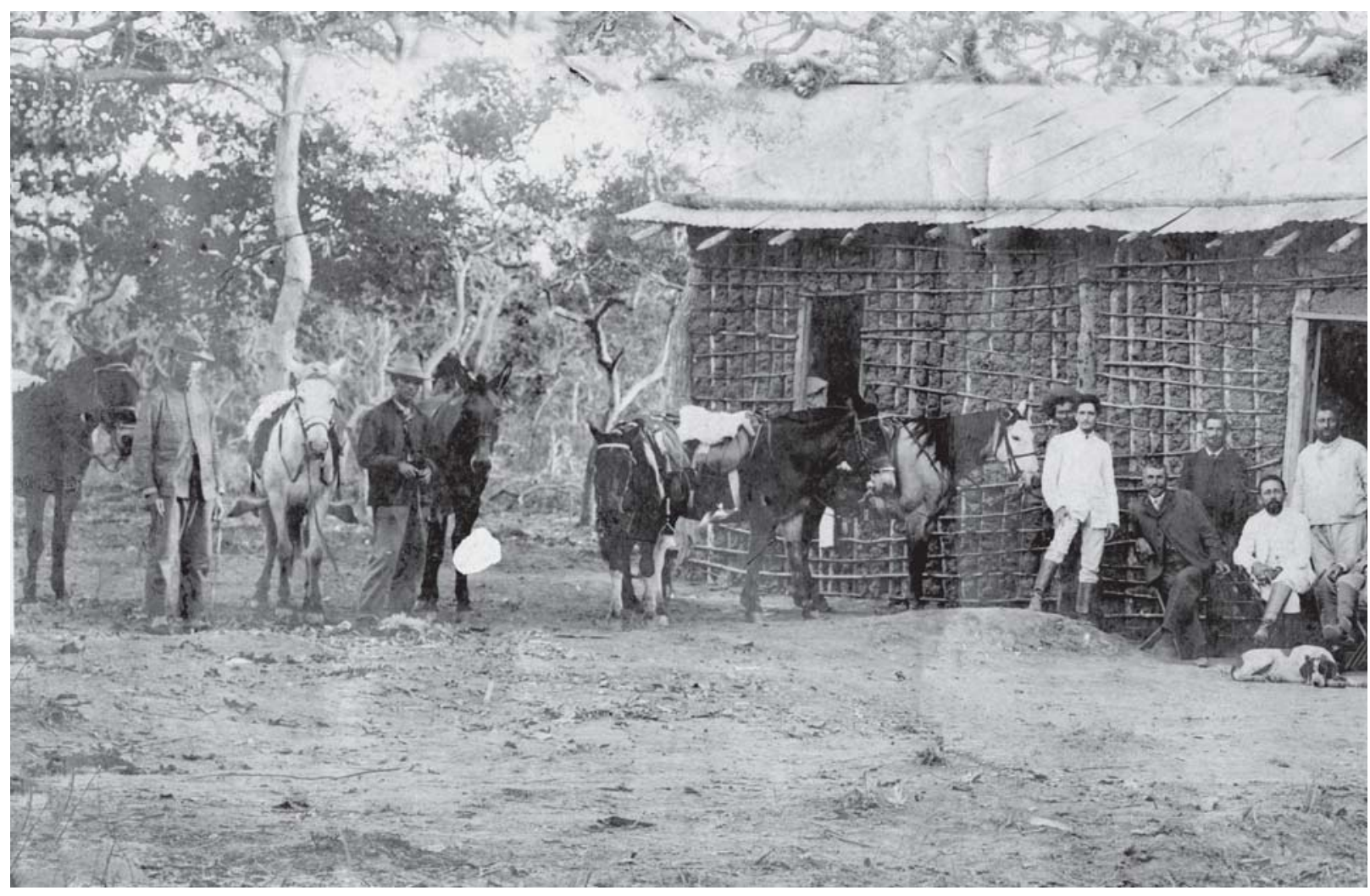




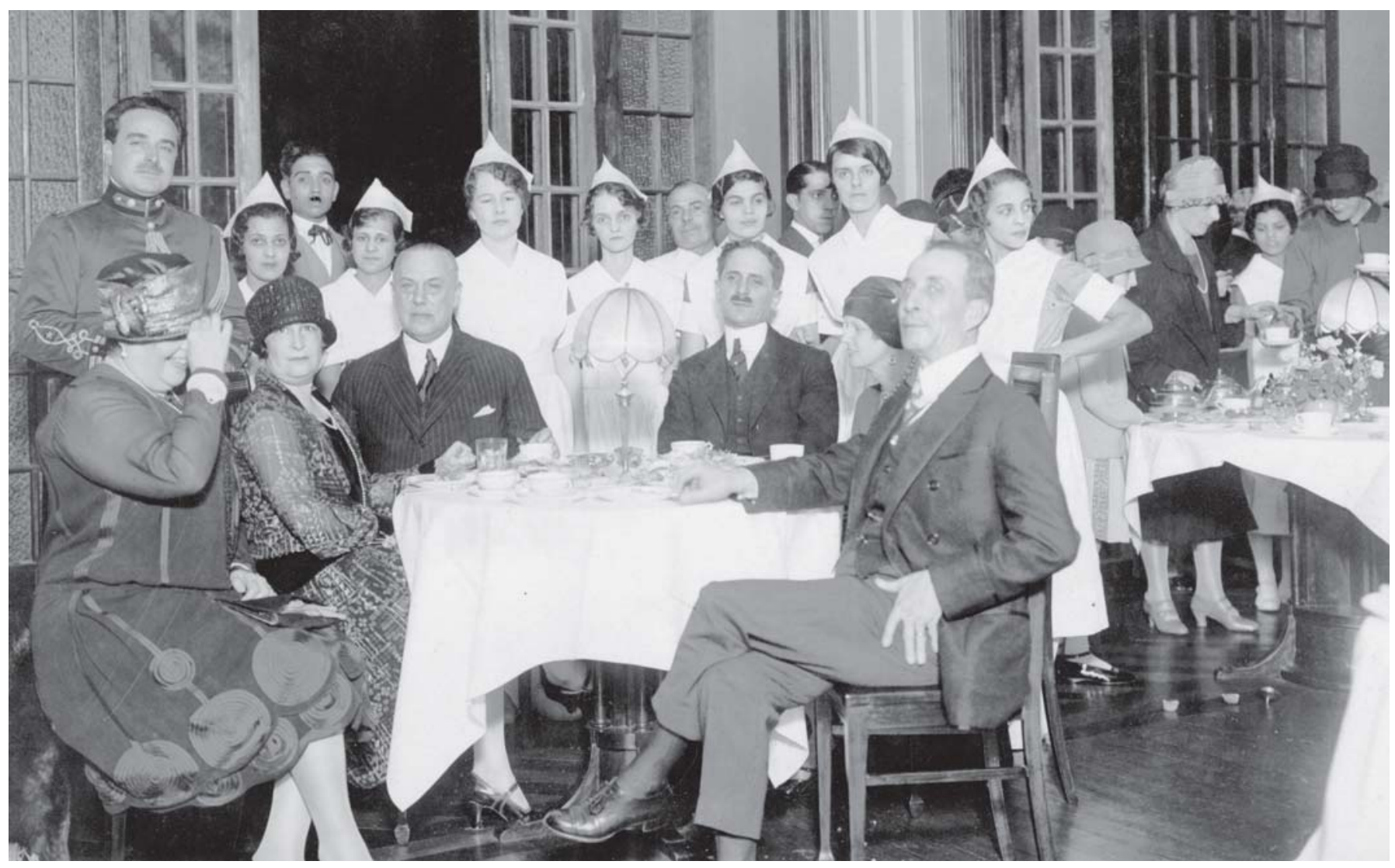

Foto 9: Carlos Chagas com Raul Leitão da Cunha, entre outros, durante solenidade em homenagem a Ethel Parsons, da Fundação Rockefeller, encarregada, junto ao governo brasileiro, de implantar o curso de formação de enfermeiras no Brasil. Provavelmente o evento ocorreu na residência da Avenida Rui Barbosa, local de hospedagem das alunas do curso de enfermagem. 29 jul. 1926.

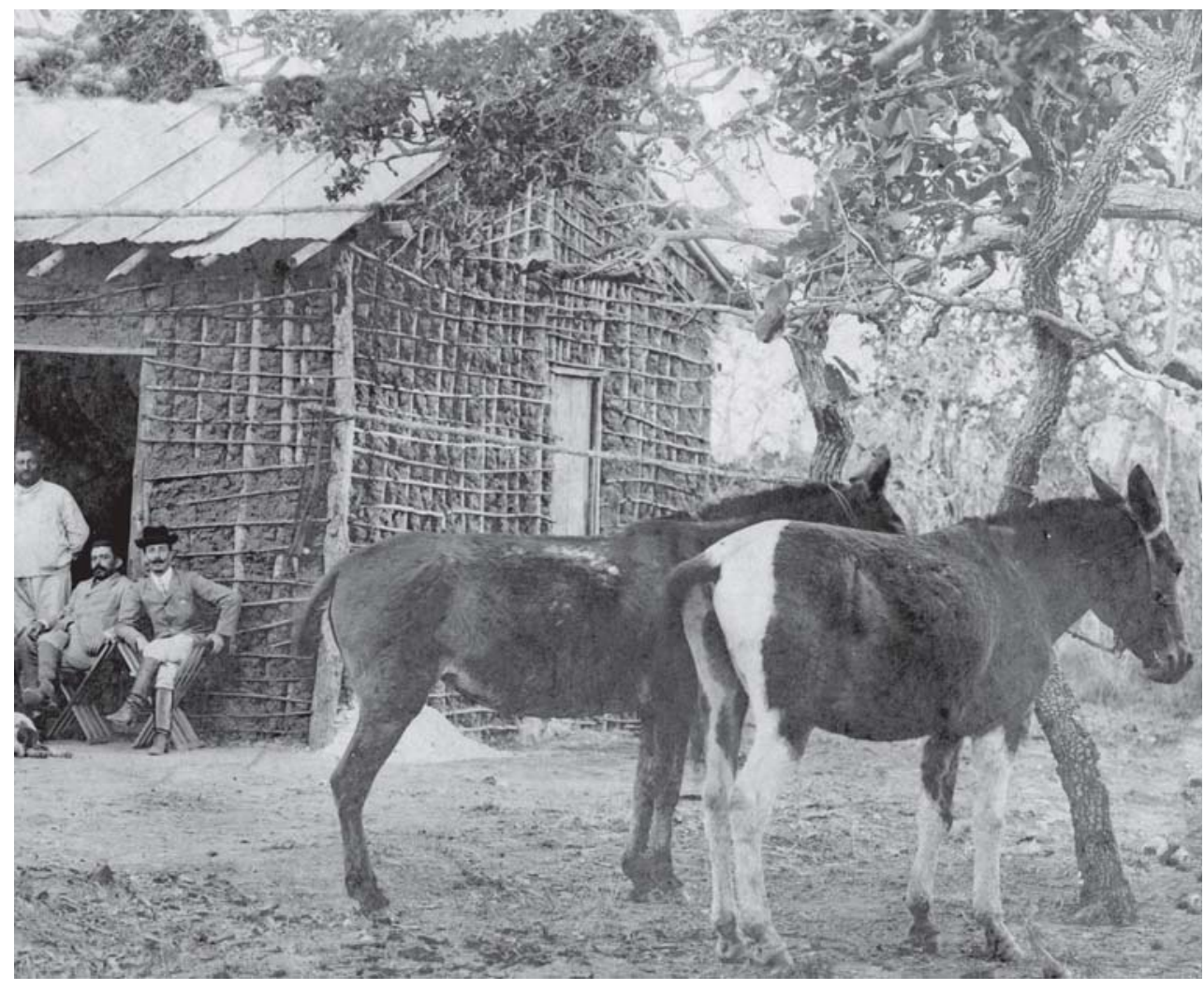

Foto 10: Carlos Chagas e Belisário Penna com a equipe que trabalhava no prolongamento da Estrada de Ferro Central do Brasil, na região do rio das Velhas, Minas Gerais. [1908?]. Sentados, da direita, Carlos Chagas, Belisário Penna, Cornélio Homem Cantarino Mota - chefe da comissão de engenheiros - e o médico Bahia da Rocha. Em pé, os engenheiros Amaral Teborge, José de Oliveira Fonseca e Joaquim Silvério de Castro Barbosa. Segundo relato de Cantarino Mota foi nessa casa, situada às margens do rio Buriti Pequeno, que o engenheiro mostrou a Chagas, pela primeira vez, os barbeiros 

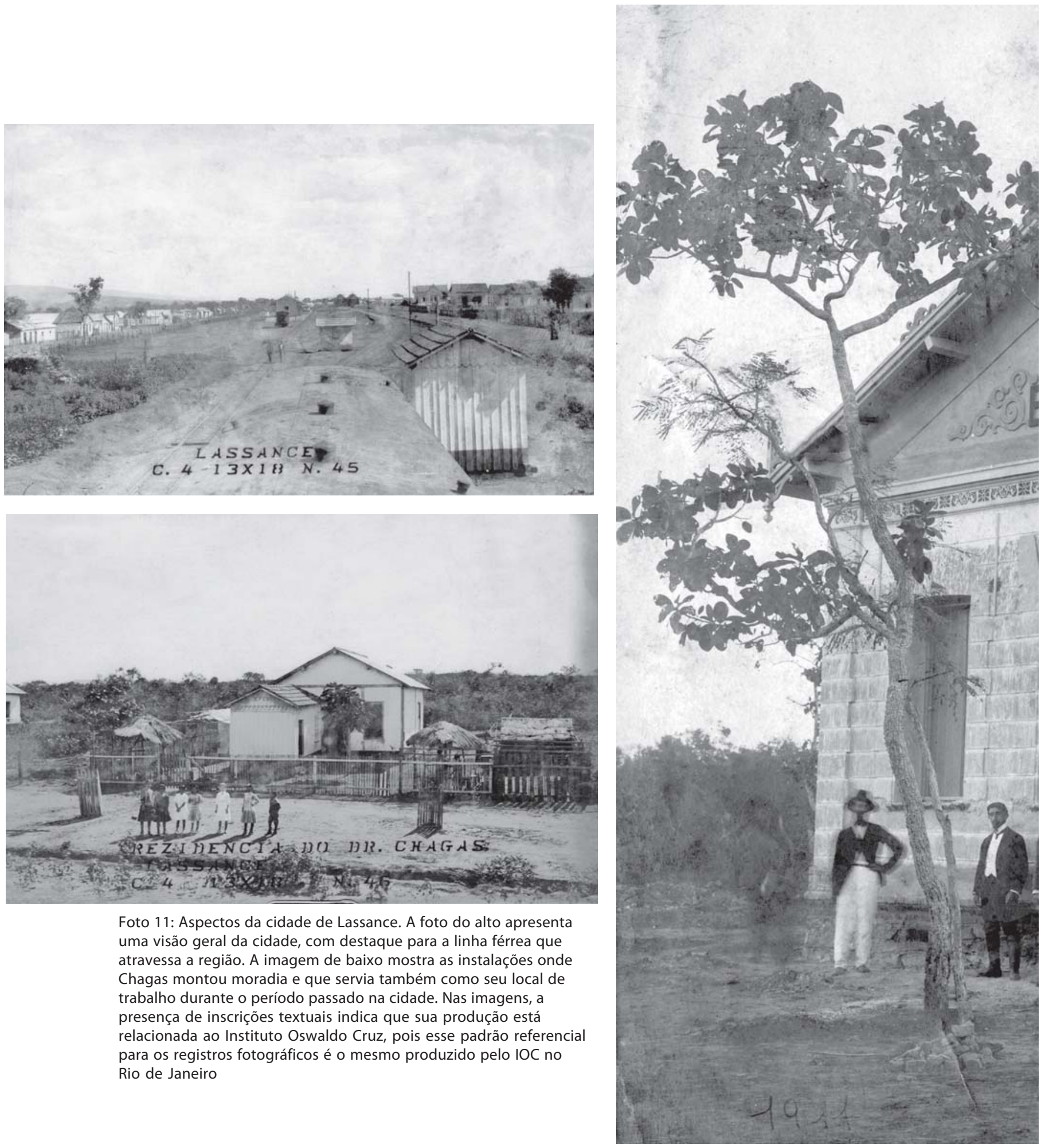

Foto 11: Aspectos da cidade de Lassance. A foto do alto apresenta uma visão geral da cidade, com destaque para a linha férrea que atravessa a região. A imagem de baixo mostra as instalações onde Chagas montou moradia e que servia também como seu local de trabalho durante o período passado na cidade. Nas imagens, a presença de inscrições textuais indica que sua produção está relacionada ao Instituto Oswaldo Cruz, pois esse padrão referencial para os registros fotográficos é o mesmo produzido pelo IOC no Rio de Janeiro 


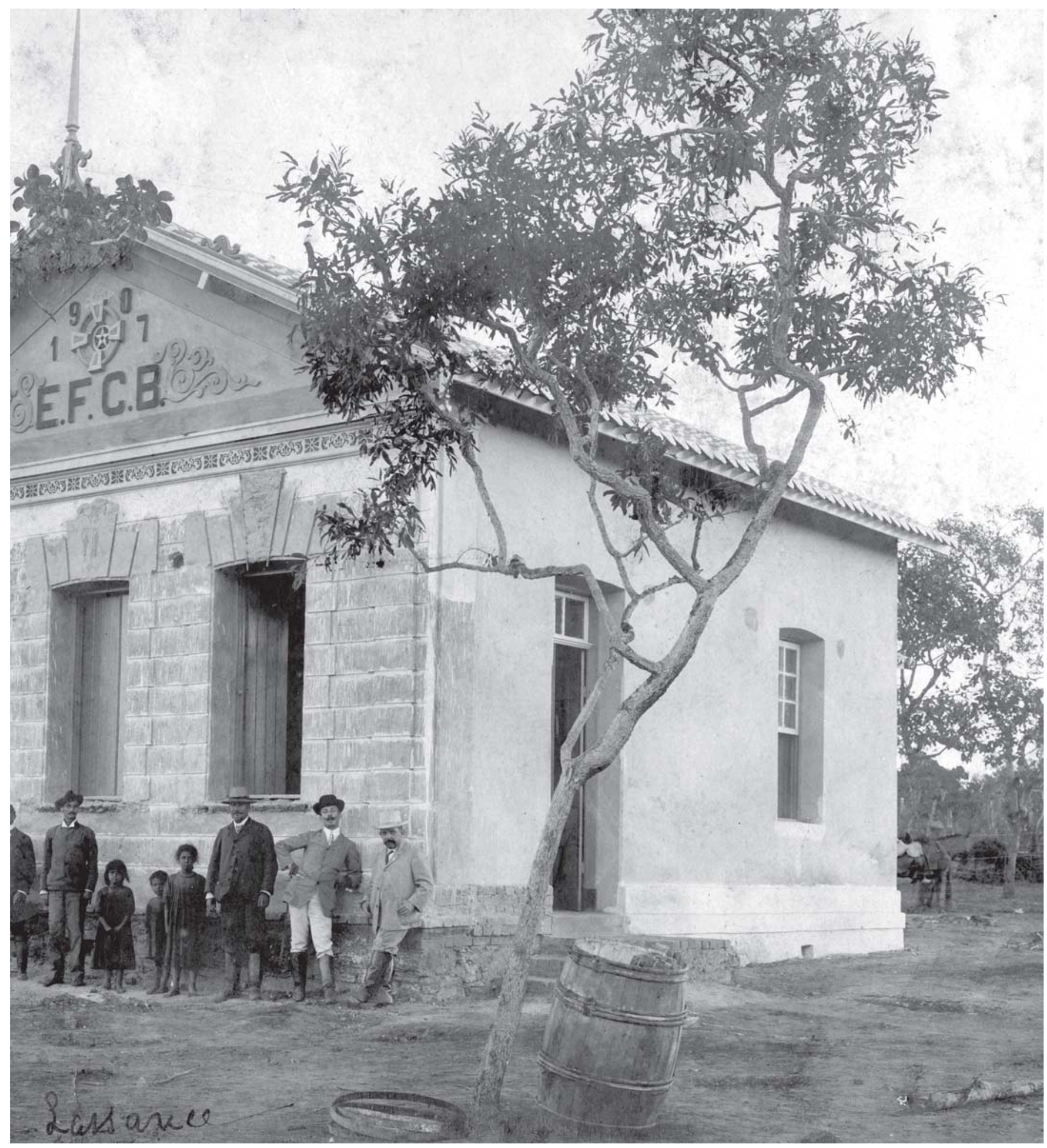

Foto 12: Carlos Chagas, Belisário Penna (ao seu lado esquerdo) e outros membros da turma de estudos do prolongamento da Estrada de Ferro Central do Brasil, em ao prédio da ferrovia. Minas Gerais, [1907?] 


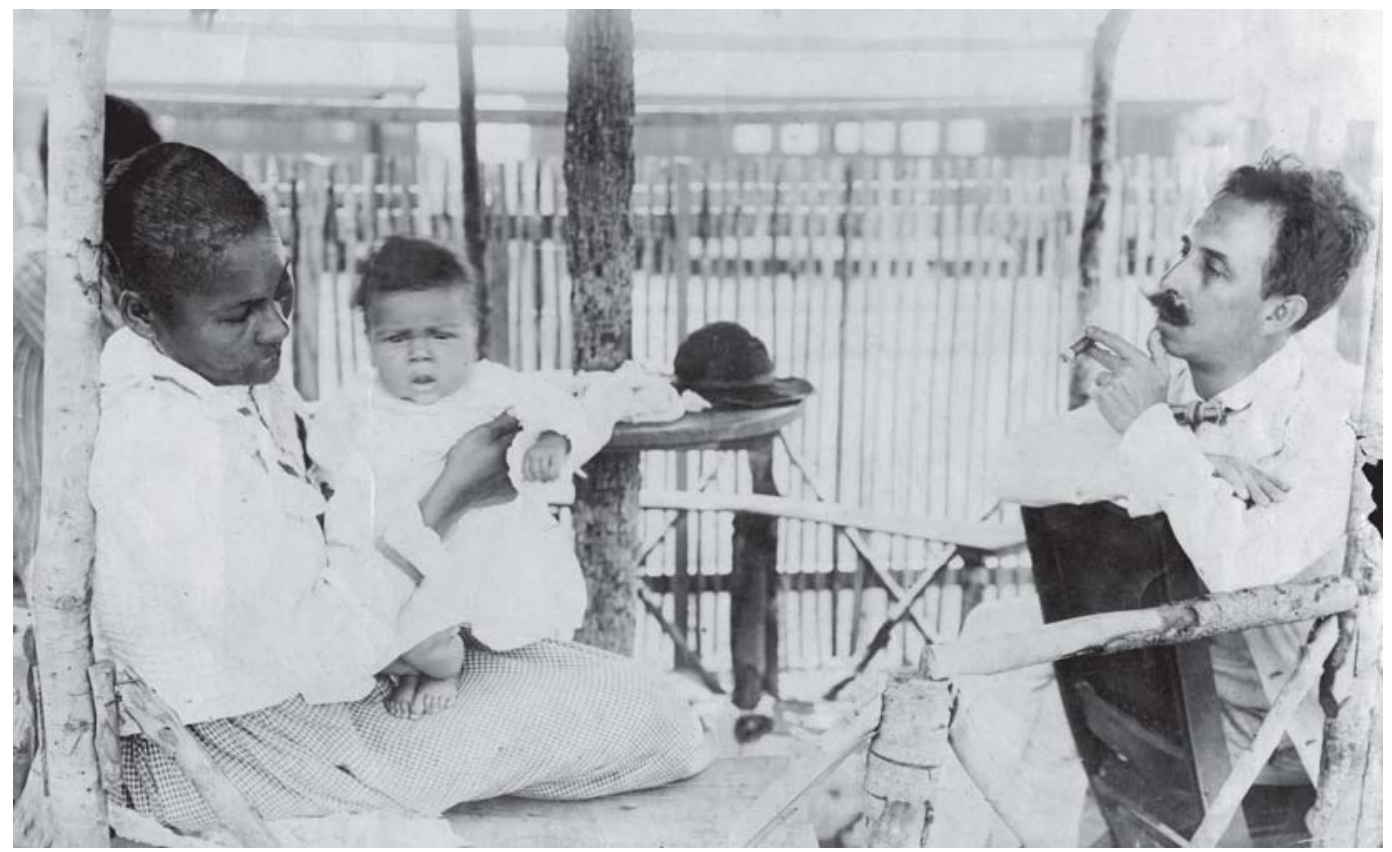

Foto 13: Carlos Chagas observa a menina Rita, um dos primeiros casos da doença de Chagas. Lassance, 1908. No livro sobre o pai, Carlos Chagas Filho comenta sobre essa imagem: "Carlos Chagas atendendo Rita, um dos primeiros casos da doença de Chagas descrito em artigo das Memórias do Instituto Oswaldo Cruz, em 1916. A garotinha, por muito tempo identificada como Berenice, morreu três dias após a consulta. Ao fundo, percebe-se o vagão que the servia de dormitório e laboratório, em Lassance". Berenice, uma criança em 1909, foi o primeiro caso descrito de doença de Chagas. Por muito tempo, Rita foi confundida com Berenice, e essa imagem usada como a representação do primeiro caso descrito da doença em humanos. Os elementos secundários da imagem - o vagão, misto de dormitório e laboratório, e o local de atendimento, uma espécie de caramanchão fortalecem a impressão da precariedade de condições dos primeiro tempos

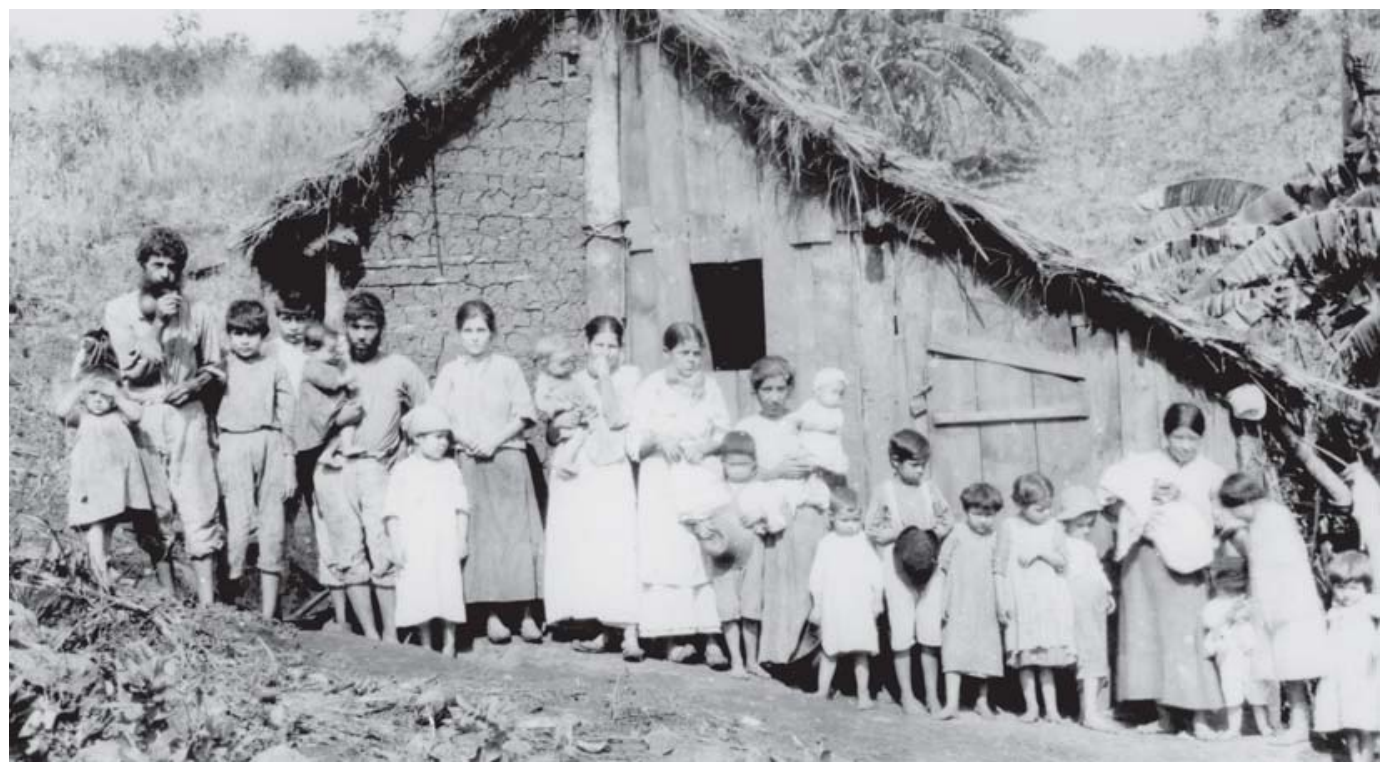

Foto 14: Aspecto de uma habitação típica da região estudada por Chagas e de membros de uma família. Percebem-se sinais de bócio, considerado pelo cientista, em seus primeiros trabalhos, um sinal clínico típico da nova tripanossomíase (hipótese mais tarde descartada) 